\title{
Canada's cod leaves science in hot water
}

The need for scientists and fishermen to develop greater trust was dramatically illustrated five years ago by events surrounding the largest collapse of a cod fishery in modern times, that of Canada's Grand Banks off the coast of Newfoundland.

The fishing area has remained closed since then, with the loss of 40,000 jobs. Alan Sinclair, of the fisheries department's Gulf Fisheries Centre in Moncton, says recovery is taking longer than expected. "There's still not much sign of recovery in areas in the Gulf of St Lawrence and off Nova Scotia."

The blame for the collapse is usually pinned on flawed models - based in part on the misreporting of data - together with political reluctance to persuade fishermen to reduce their catches in line with scientific recommendations.

Before the collapse, scientists would set a 'total allowable catch' each year based in part on assessments of fish stocks from reported commercial catches, and in part on data from scientists' own research vessel.

\section{Data supported opposing views}

The two sets of data did not always tally. The scientists' stock assessment would invariably be lower than data from the fishermen. The explanation was simple: fishermen went to warmer waters where cod were found, while the scientists traversed a random path. As a result, however, fishermen would insist there were enough fish in the sea - a message that invariably had the ear of the policymakers.

Bill Doubleday, director general for science in Canada's federal oceans and fisheries department, says the department has addressed the problem of mistrust by involving fishermen in the evaluation of stock assessments, as well as in collecting data.

In what are called 'sentinel surveys', the fishermen follow a scientific protocol, catching a small amount of fish according to an experimental design, mainly with fixed gear. In addition, some fishermen using mobile gear carry out deeper surveys at their own expense. "I think it was mainly having fishermen participate in the reviews that has defused the issue. It has helped very substantially, because now they understand what went on," Doubleday says.

Tensions between scientists and fishermen have not been eliminated by this strategy. But instances of public disagreement have been significantly reduced. "We've changed our perspective from ten years ago, when there was a tendency to err on the side of the fishermen. Now if we are going to err we err on the side of maintaining enough fish in the water."

Yet there were other reasons for the collapse, and workshops have been held to examine the methods used in stock assessment at the time. Scientists say that here, too, many

lessons have been learned. "We have tried to correct them by dockside monitoring and audits and also to understand how our models are performing," says Sinclair. "There are also techniques used that don't use commercial data at all."

Another factor in the collapse is thought to have been the failure to understand the variable mortality rates of cod. The populations of Canadian cod were considered robust, as they would always bounce back after depletion occurred.

"The red flag wasn't waving as hard [as in Europe's North Sea] and for a brief period in the late 1980 s and early 1990 s there were attempts to phase in reductions in the fisheries over a period of years," says Sinclair. "By that time the evidence was really strong that there was a problem, and Canada closed the fishery down."

According to Doubleday, the Canadian cod stocks turned out to be less robust than had been thought. "Our level of exploitation was too high for those circumstances, even though it was nowhere near as high as in the North Sea."

Both Sinclair - the co-author of a recent paper (see Nature 385, 521-522; 1997) arguing that the rate of exploitation of North Sea cod is unsustainable - and Doubleday believe that the Grand Banks collapse cannot be compared to the North Sea.

Doubleday points out that the Canadian cod were in a very cold part of the ocean, with bottom temperatures of $-1.4{ }^{\circ} \mathrm{C}$, while North Sea cod are in waters that do not fall below $4{ }^{\circ} \mathrm{C}$. Cod stocks are larger where water is relatively warm.

But they point out that catches are much larger in the North Sea than they were in Canada. North Sea cod tend to grow quickly,

\section{Overfishing is a global threat, warns FAO}

The State of World Fisheries, the latest report from the United Nations Food and Agriculture Organization in Rome, could make even the most eager fish gourmet think again before placing their next order. More than two-thirds of the world's species - including favourites such as cod, lobster, prawn and shrimp - are variously being fished to capacity, overfished or are recovering from overfishing.

The organization predicts that world fish production will remain fairly constant at around 90 million tonnes per year up to 2010. But, with world population expected to reach 7 billion by this time, fish supplies will be hit by a 19-million-tonne shortfall, expected to be met by fish farming.

Eighty per cent of the world's marine catches are taken by 20 states. China, Japan and North and South Korea account for almost one-third of the world's total fish
The way it was: full catches, seen here in Ireland, are little more than memories in parts of Canada.

says Sinclair, but they are caught at age two, before they mature sexually. And if fish spawning should fail for two years in succession the fishery could be reduced rapidly.

"Some consider it amazing that the North Sea cod survive because the fish are taken before the age of four years and the fishing pressure is very high," says Doubleday.

"One thing they might do is increase the size at which they are caught," suggests Sinclair. "This could be accomplished by increasing the size of the net mesh. But a problem is that the catch includes whiting, which are smaller than cod, and these might belost with a larger mesh." David Spurgeon

consumption. Forty per cent of the world's 25,000-strong fishing fleet is in Asia, followed by 30 per cent in the former Soviet Union, 10 per cent in North America and 12 per cent in Europe.

China heads the international league for fish production. Fifteen million tonnes were produced in 1992, much of it for export. Japan is second at 8.5 million tonnes. But the Japanese eat more fish, reaching a total of 70 kilograms per person per year. Peru and Chile both catch more fish than the United States -8.5 and 6 million tonnes respectively.

In the European Union, fish production increased from 8 million tonnes in 1984 to 9.5 million tonnes in 1992. Average consumption per person is now 22 kilograms - the same as in the United States and Canada, which together catch 7 million tonnes of fish per year. 